\title{
FEMINISMO, GÊNERO E OS ALCANCES DA LEI MARIA DA PENHA
}

\section{FEMINISM, GENDER AND THE POSSIBILITIES OF MARIA PENHA LAW}

\author{
${ }^{1}$ Marcela Dias Barbosa \\ ${ }^{2}$ Paulo César Corrêa Borges
}

\section{RESUMO}

O presente artigo pretende discutir os limites e possibilidades da Lei Maria da Penha ou Lei 11.340/2006, no Brasil, a partir de uma perspectiva crítica e feminista. A integralidade da lei permitiu um amplo tratamento das mulheres vítimas de violência doméstica ou intrafamiliar e logrou o reconhecimento do espaço privado enquanto um local político, devendo abranger também as instituições. Embora a abordagem jurídica tenha avançado ainda enfrentam-se obstáculos em sua aplicabilidade tendo em vista o impedimento produzido pelo imaginário androcêntrico presente no direito e em todos os outros espaços de sociabilidade, estruturados e dominados simbolicamente pelo patriarcado.

Palavras-chave: Lei maria da penha, Violência doméstica ou intrafamiliar, Feminismo, Gênero

\begin{abstract}
This article discusses the limits and possibilities of the Maria da Penha Law or Law 11.340 / 2006 in Brazil, from a critical and feminist perspective. The entire Law allowed a broad treatment of women victims of domestic violence or intra-family and managed the recognition of private space as a political site, should also cover institutions. Although the legal approach has advanced still face obstacles to their applicability in view of the impediment produced by androcentric imagery present in the law and in all other social areas, structured and symbolically dominated by patriarchy.
\end{abstract}

Keywords: Maria da penha law, Domestic or family violence, Feminism, Gender

\footnotetext{
${ }^{1}$ Mestranda em Direito pela Faculdade de Ciências Humanas e Sociais, Universidade Estadual Paulista - UNESP, São Paulo, (Brasil). E-mail: tutortreinamento@gmail.com

${ }^{2}$ Doutor de Direito Penal e Criminologia pela Universidade Estadual Paulista - UNESP, São Paulo,

(Brasil). Professor Assistente pela UNESP. E-mail: tutortreinamento@gmail.com
} 


\section{INTRODUÇÃO}

A partir de uma leitura crítica e feminista, este artigo pretende discutir os limites e possibilidades da Lei 11.340/2006 ou Lei Maria da Penha, bem como sua integralidade. Com intuito de tornar público o local que historicamente esteve sacralizado e protegido de qualquer intervenção externa, a família, os movimentos feministas, a sociedade civil organizada e iniciativas em torno dos tratados internacionais lograram a promulgação de uma normativa visando o combate à violência doméstica ou intrafamiliar contra as mulheres. Notoriamente o problema adquiriu dimensão pública e política, passando a ser responsabilidade de todos os cidadãos e todas as cidadãs, juntamente do Poder Estatal, coibir às violências perpetradas contras às mulheres, no Brasil.

Foi conquistada, pela primeira vez, uma lei com objetivo combater os variados tipos de violência contra a mulher, buscando uma intervenção ativa, incisiva e em outros casos educativa para por fim a discriminação de gênero ainda tão presente nos lares brasileiros. Criaram-se mecanismos para gerar garantias jurídicas e sociais no âmbito do direito, além de explicitar as consequências da enraizada cultura patriarcal presente em todos os espaços de sociabilidade humana.

A Lei 11.340/2006 surge num contexto de euforia e otimismo, afinal foi resultado da luta de mais uma Maria do Brasil que sofreu duas tentativas de homicídio, restando paraplégica, e chegou até mesmo a pensar que "[...] se não aconteceu nada até agora, é porque ele, o agressor, tinha razão de ter feito aquilo.” (DIAS, 2008, p. 13) Foi um momento histórico de vitória e empoderamento feminino já que as instituições sociais estavam unidas para concretizar os direitos humanos das mulheres e finalizar com a violência cíclica e estrutural atentatória a dignidade de todas.

O tratamento da violência doméstica no Brasil enquanto um problema de gênero trouxe como avanço a demonstração jurídica desta categoria de análise e como consequência à assunção de que o feminino e o masculino não são dados naturais ou biológicos, mas sim construções culturais com carga política. Ou seja, as características atribuídas a cada gênero e valoradas de forma desigual, não são nenhuma pré-destinação da natureza que condenam a mulher a ser um ser social vitimizado e infravalorado.

A Lei Maria da Penha inovou com as previsões de criação dos Juizados de Violência Doméstica e Familiar contra a Mulher, a não incidência da Lei 9.099/1995 (BRASIL, 1995, online), o rol de medidas protetivas, o trabalho em rede dos diversos órgãos públicos em torno da questão de gênero, entre outras importantes garantias. Trouxe polêmica e divergências em 
razão de juristas que se posicionaram contra a normativa, o que foi pacificado por decisão proferida pelo Supremo Tribunal Federal, esclarecendo que a lei não fere os princípios constitucionais e, portanto, não possuí vício de inconstitucionalidade. Contudo, o problema cultural e milenar do patriarcado, existente também num plano simbólico e relacional ainda apresenta-se como impedimento à aplicabilidade de leis como a Maria da Penha ou qualquer outra reconhecedora às mulheres como sujeitos capazes e dotados de direitos.

Desta forma, conclui-se que a incorporação da Lei Maria da Penha no ordenamento brasileiro foi uma conquista importante, porém, pontual e insuficiente se restrita apenas ao campo do formalismo jurídico. Faz-se necessária a construção de um novo imaginário dentro do direito desde os aportes fornecidos pelas teorias críticas feministas a fim de romper com o androcentrismo em todos espaços de sociabilidade. Uma vida digna e livre de violências para todas as mulheres brasileiras só será possível ao conscientizarem-se todos os indivíduos de que elas também são humanas.

\section{CONCEITO DE GÊNERO}

Ao iniciar uma análise da normativa brasileira é elementar desmistificar idéias petrificadas através de comportamentos e papéis construídos pelo pensamento androcêntrico, explicitando suas raízes e expressões de desigualdade. A desnaturalização da opressão das mulheres, necessariamente passa pelo conceito de gênero, inaugurado pela antropóloga estadunidense Gayle Rubin (2008) em seu livro O Tráfico de Mulheres: Notas sobre a “Economia Política do Sexo”.

A autora reflete sobre as relações que tornarão uma fêmea da espécie humana em uma mulher domesticada, afastando das explicações biológicas à atual configuração patriarcal que subjuga às mulheres. Aproxima sua análise ao que chamou de um sistema sexo/gênero, $a$ priori neutro, já que significará apenas diferenças socialmente construídas a partir do sexo, sem estar incluído necessariamente em seu sentido a dominação de um pelo outro. Esta última faceta surge da apropriação de nosso modelo político-econômico ao sistema de gênero desde dinâmicas de opressão e controle ao corpo feminino.

Segundo Rubin (apud OSBORNE; PETIT, 2008, p. 163):

Eso sistema puede ser sexualmente igualitario, por lo menos en teoría, o puede ser estratificado por géneros, como parece suceder con la mayoría o la totalidad de los ejemplos conocidos. Pero es importante- aun frente a una historia deprimente-mantener la distinción entre la capacidad y la necesidad 
humana de crear un mundo sexual. El término patriarcado subsume ambos sentidos en el mismo término. Sistema de sexo/género, por otra parte es un término neutro que se refiere a este campo e indica que en él la opresión no es inevitable, sino que es producto de las relaciones sociales que lo organizan.

A idéia acima trabalhada já havia sido refletida, anos antes, em 1949, pela notável feminista Simone de Beauvoir quando escreve suas famosas palavras: "não nasce mulher, se faz". A fase do renascimento feminista, pertencente aos anos 60, deixa explícito o conceito gênero e a idéia de que a partir das diferenças sexuais são atribuídas características e significados que definirão uma mulher e um homem em seus papéis sociais, comportamentos e valores. A feminista afastava das explicações das ciências biológicas estes feitos já que não estava incorporada na genética feminina a sua identidade sexual, não sendo possível naturalizar uma desigualdade construída pelos próprios seres humanos.

Ainda neste sentido, diz Gargallo (2004, p. 59) que:

[...]para Graciela Herrero la categoría central aplicable a la condición feminina es la de "ser para otro" que, según Beauvoir, la situaba en un nivel de inferioridad respecto al otro sexo, negándole toda posibilidad ontológica de transcendencia. „El ser para otro del que nos habla Beauvoir se manifiesta concretamente en la mujer a través de su situación de interiorización, control y uso".

Deste modo, teorias latinoamericanas surgidas, depois do ano de 1972, coincidem nas afirmações sobre a criação da identidade sexual e de gênero como a sociedade participa deste processo. A maioria converge em constatar que uma importância exagerada é dada as diferenças biológicas, enquanto se invisibilizam as similitudes entre os sexos, de modo a educar e socializar de acordo com a genitália da criança. (MONTEJO; FRIES, 1999, p. 33) Às crianças com genitália feminina já nascem condenadas a uma personalidade única, limitada e pouco valorada. Ao serem enfeitadas pelos pais com adornos rosados, brinquedos que visam formar uma futura dona de casa, com as contínuas afirmações (histórias contadas oralmente, desenhos, contos infantis, entre muitos outros) de que sua maior aspiração é o casamento, o exemplo de suas mães submissas às ordens do marido e todos estes fatores sociais- não naturais- eliminam as possibilidades de uma mulher constituir-se independentemente de outro ser humano e desde seus sonhos e desejos individuais.

Enquanto relegamos as mulheres ao destino previsível da invisibilidade ou de meras coadjuvantes em um mundo protagonizado pelo homem e a masculinidade imperante, estes últimos para afirmarem-se jamais podem demonstrar comportamentos que fogem a regra da 
agressividade, racionalidade, altivez, virilidade, etc. Ou seja, ambos os sexos terminam prejudicados com este dinâmica já que são eliminadas de suas vidas as variadas formas de sentimentos, condutas humanas, pensamentos que não estejam vinculados a seu gênero. No entanto, vale salientar que os maiores danos neste ínterim são às mulheres por ocuparem o papel de seres humanos oprimidos em meio a esta relação de poder.

Nas palavras de Alda Facio Montejo e Lorena Fries (1999, p. 43):

La jerarquización de estos valores a favor de lo masculino tiene consecuencias negativas para la sociedad en su conjunto y no sólo para las mujeres. La sobrevaloración de la producción es lo que nos ha llevado a sociedades consumistas que sólo necesitan la reproducción humana para que haya mano de obra barata y más y más personas que consuman. La sobrevaloración de la cultura nos ha llevado a la explotación destructiva de la naturaleza, la infravaloración de la dulzura, la interdependencia, la intuición y de los roles asociados con el cuidar, nutrir y dar. Nos está llevando a sociedades cada vez más violentas y egoístas. Peor aún, la invisibilización de la dicotomía en nuestra forma de pensar y entender el mundo nos ha llevado a no ver por qué estamos como estamos y por ende a no poder encontrar soluciones adecuadas a los problemas que hoy enfrentamos.

Portanto, a categoria gênero descrita acima diz respeito a uma categoria histórica, que se expressará de distintas formas em cada sociedade ou grupo humano, dependendo dos fatores da realidade que neste concursam. Ademais, não possui em seu conceito, necessariamente, o vetor que aponta a desigualdade entre homens e mulheres. Ainda que este esteja presumido em nosso atual sistema político-econômico de exploração, é importante ressaltar que o responsável por tal verticalização é a categoria específica do patriarcado.

Datado de seis ou sete milênios, o patriarcado foi imposto como modelo que se adaptou aos diversos períodos da história da humanidade. Desde a Grécia antiga, quando a mulher era considerada um ser incompleto pela ausência do órgão genital masculino até a recente história latinoamericana em que novos modos de violência patriarcal se manifestam assustadoramente das mais variadas formas. Lamentavelmente, ainda impera um modelo no qual há a primazia do masculino em detrimento da liberdade e autonomia da mulher, configurando uma relação de poder que historicamente violou direitos de metade da humanidade impunemente, assim como pontua Cobo (2011, p. 148):

[...] todas estas manifestaciones de violencia contra las mujeres, a pesar de tener motivaciones contextuales y culturales específicas en cada caso, brotan de la misma fuente. Y la fuente está en el centro mismo de esa macroestructura de dominio masculino que denominamos patriarcado. 
Alguns autores reverberam a tese da construção social dos gêneros através de pesquisas empíricas como a realizada pelo psiquiatra Robert Stoller em seu livro "Sex and Gender". Este estudou o caso de dois gêmeos idênticos, especificamente, um deles que teve acidentalmente o seu órgão genital amputado. A família e os médicos confusos quanto ao sexo que deveriam designar a criança, preferiram ao final socializá-lo como uma menina. A criança, portanto, cresceu com a identidade sexual de uma menina enquanto seu irmão gêmeo vivia como um menino. Este fato fez Stoller $(1968$, p. 7) aprofundar nos seus estudos e concluir que a identidade sexual não sempre é definida a partir do sexo.

O psiquiatra se refere a gênero como umas das “[...] grandes áreas de la conducta humana, sentimentos, pensamentos y fantasias que se relacionam con los sexos pero que no tienen una base biológica." Isso demonstra que o sexo possui carga valorativa e cultural, sendo ele o elemento a definir os mais íntimos desejos de cada ser humano, suas aspirações e comportamentos. O fator que determinará a identidade sexual, portanto, não é o sexo biológico mas sim, o ser socializado, desde o nascimento ou antes, como pertencente de um ou outro sexo (MONTEJO; FRIES,1999, p. 32).

As ideias produzidas e reproduzidas sobre os gêneros são habilmente construídas pela ideologia e instituições patriarcais como características opostas e complementares. No entanto, uma escala de poder é delineada de tal modo que as mulheres ocupam a posição de subordinadas. Este fato se intensifica ainda mais, se for uma mulher negra, pobre, homossexual, estrangeira, maior de idade, com alguma deficiência física, entre outros. Tal configuração é consolidada por meio da linguagem sexista, a mídia machista, a educação excludente, a documentação somente da história dos homens, a religião que controla o corpo das mulheres e os valores patriarcais presentes em todos os espaços de sociabilidade.

Toma-se uma parte para representar o todo. Nunca foi necessário pelos códigos incluir em sua linguagem o sexo feminino já que este "naturalmente" estaria abarcado pelas afirmações sobre os homens. O que ocorre na verdade, não é uma incorporação da mulher no mundo masculino, mas sim a supressão deste grupo social e suas demandas.

Os estereótipos de gênero direcionados as mulheres se contrapõe aqueles atribuídos aos homens. Como dito, estes são completamente distintos e se complementam, porém significam para o grupo feminino uma forma de controle e opressão ainda mais intensa e danosa que para os homens. Aqueles identificados como do sexo masculino exercem o poder e ocupam uma posição privilegiada no campo social. Ao sofrer qualquer tipo de ameaça este 
poder imposto pelo "macho" justifica os mais brutais atos de violência e violadores de direitos fundamentais.

Os modelos de gênero são atravessados por algumas idéias fundamentais em torno da violência. Primeiro, desta como um fenômeno estrutural estabelecida pelas relações de gênero em um sistema patriarcal. Segundo, como um mecanismo de controle sobre todas as mulheres, atendendo ao princípio de que "[...] enquanto haja somente uma mulher agredida, qualquer outra pode ser." Ademais, representa um continuo de condutas consideradas "normais" que se explicam pela grande tolerância ainda existente quanto a atos de agressividade (OSBORNE, 2009, p. 18).

Em suma, o discutido sistema patriarcal se desenvolve no seio da sociedade capitalista e faz parte de um conjunto de relações entre homens e mulheres. Portanto, tanto os homens como as mulheres são parte ativa da estrutura básica patriarcal, não podendo ser responsabilizados pela construção do nosso imaginário social apenas aqueles do sexo masculino. Ainda que estes últimos sejam os beneficiários desta dinâmica social, as mulheres também devem ser vistas como agentes que protagonizam o processo de formação de uma ideologia sexista. É fundamental considera-las como seres integrantes e ativos nas tramas sociais tanto de emancipação quanto de opressão para que se possa vislumbrar a libertação do feminino.

\section{RELAÇÕES DE GÊNERO A PARTIR DE UMA PERSPECTIVA FEMINISTA}

Neste trabalho parte-se do entendimento que as dicotomias e o modelo cartesiano de análise devem ser repensados em razão da historicidade e dinamicidade do corpo social. Assim, o conceito gênero será trabalhado não apenas com as oposições sexo (elemento estático) e gênero (elemento cultural), mas sim, como relações em constante transformação e numa indissociável influência. Não se pode pensar o gênero sem o sexo, tampouco o contrário, já que "[...] a cultura não somente atribui e constrói o gênero, mas também que cria e inventa o sexo!” (MONTEJO; FRIES, 1999, p. 35, tradução nossa).

Desta forma, será adotado o termo "relações de gênero" para dar ênfase ao caráter relacional do conceito e romper com a idéia de que este é construído desde algo imutável, o sexo. Tanto o sexo quanto o gênero se fazem e refazem historicamente, são dotados de sentido e carga ideológica, além de estarem em constante relação.

Desenvolvendo ainda mais as terminologias, Heleieth Saffioti (1997, p. 4) utilizará como explicação a nossa configuração social o tripé da ideologia dominante ou "nó" 
sustentado por opressões que se sobrepõem e intensificam. Este nó envolve o fator raça/etnia, classe social, gênero e trata de hierarquizar as relações entre mulheres brancas, mulheres negras, mulheres brancas e ricas, mulheres negras e pobres, colocando no ápice da pirâmide social, obviamente, aqueles que são homens, brancos, ricos, heterossexuais, cristãos, em idade produtiva, etc.

É importante não recair no erro da homogeneização e esquecimento das especificidades existentes num estudo que pretende a reconstrução dos direitos humanos desde uma perspectiva crítica e feminista. É um fato concreto a opressão de gênero na vida de todas as mulheres, sejam elas negras, brancas, pobres, ricas, imigrantes, indígenas, etc, contudo é fundamental a constatação de que cada uma sofre de diferentes maneiras esta subordinação.

Para Alda Facio Montejo (1999, p. 34):

[...] la sociedad no construye a todas las mujeres idénticamente subordinadas ni a todos los hombres con los mismos privilegios aunque sí en su universalidad las mujeres son subordinadas por los hombres. Es difícil reconocer que la mujer de clase alta, en edad productiva, adinerada, sin discapacidades visibles, blanca, esposa de un banquero, pueda compartir la subordinación de género con una mujer pobre, vieja, discapacitada, lesbiana y negra. Pero así es. Ambas comparten el mandato de ser para un hombre, dedicarse centralmente a los hijos y a la casa; ambas son invisibilizadas por el lenguaje, marginadas de la historia, y permanentemente víctimas potenciales del abuso y acoso sexual. Ambas viven en un mundo que simbólicamente las aniquila y que constantemente les recuerda que ser mujer es no ser persona y sin embargo cada una pertenece a una cultura que representa de distintas maneras esta subordinación.

Partindo destes conceitos principais, está claro que a perspectiva adotada é a de gênero e, assim, será denunciado como o direito e a prática dos juristas toma o homem de referencial a seu conteúdo e o apresenta como único, universal e neutro. O direito não está dissociado das relações de gênero e delas se apropria usando a ideologia do patriarcado. A proposta de uma nova perspectiva, que seja gênero sensitiva, é justamente sugerir distintas formas de construir os gêneros que não estejam fundadas na discriminação e colocar as relações de poder entre homens e mulheres no centro de qualquer análise e interpretação da realidade.

Vale ressaltar, que a iniciativa de rompimento com os modelos dicotomizados e desiguais foi tarefa incorporada pelos movimentos feministas, que além de teorizarem sobre o sistema sexo-gênero, atuaram politicamente no sentido de promover mudanças substanciais. 
Estes movimentos foram os mais significativos do século $\mathrm{XX}$, aparecendo como ideologia plural e diversa, com o objetivo principal de superar a situação de subordinação de todas as mulheres do mundo. Os estudos feministas são desenvolvidos para que na prática sejam aplicados como direcionadores da política feminista.

O jovem movimento é conceituado por Castells (1996, p. 10) como:

[...] lo relativo a todas aquellas personas y grupos, refexiones y actuaciones orientadas a acabar con la subordinación, desigualdad, y opresión de las mujeres y lograr, por tanto, su emancipación y la construcción de una sociedad en que ya no tengan cabida las discriminaciones por razón de sexo y género.

Ainda sobre a igualdade almejada pelos movimentos feministas não seria esta por idêntica capacidade e direitos que os homens possuem. Pelo contrário, lutam pelo reconhecimento de suas diferenças como dotadas de mesma importância às do sexo masculino e não meramente como características "específicas" a serem tratadas pelos códigos. Ou seja, os feminismos buscam o fim das ideologias e estruturas androcêntricas que colocam o homem como modelo único e central de ser humano. Em consonância com o pensamento de Boaventura de Sousa Santos, a utopia feminista carrega o sentido de que:

Temos o direito a ser iguais quando a nossa diferença nos inferioriza; e temos o direito a ser diferentes quando a nossa igualdade nos descaracteriza. Daí a necessidade de uma igualdade que reconheça as diferenças e de uma diferença que não produza, alimente ou reproduza as desigualdades. (SANTOS, [2008], online).

Deste modo, os movimentos feministas trataram de explicitar a opção do direito pelos interesses masculinos ocultados pela pretensa universalidade de seu discurso. Ademais, deixa claro que este trata os casos de discriminação baseadas no sexo como algo natural, não a serem solucionados, mas sim reforçados. Tem-se como exemplo os recentes códigos civis, superados há pouco tempo, que diziam ser a mulher indivíduo "relativamente" incapaz em razão da sua natureza débil e impeditiva de tomar decisões na vida jurídica.

E o papel do feminismo é justamente explicitar essas diferenças reforçadas pelo direito e ressaltar o sentido da existência humana. Este movimento político e social parte do entendimento de que a harmônia e liberdade feminina são mais importantes que a acumulação de riqueza instituída pelo capitalismo e seus ideais machistas. Assim como a opressão, desumaniza, o opressor perde seu sentimento de pertencimento a sociedade quando oprime 
outra vida. Por isso, os ideais feministas se opõe ao poder instituído sobre as mulheres, ou qualquer outro ser humano, em situação de desigualdade.

\section{LEI MARIA DA PENHA: VEDAÇÃO DA APLICABILIDADE DOS JUIZADOS ESPECIAIS CRIMINAIS E CONSTITUCIONALIDADE DA LEI}

O combate à violência doméstica ou intrafamiliar é assunto amplamente discutido pelos movimentos sociais feministas desde meados dos anos 70. Os números alarmantes de mulheres agredidas por seus companheiros e a omissão das instituições governamentais diante destes casos demonstraram a necessidade de uma abordagem crítica e comprometida com a realidade no campo jurídico e social. A partir de então, foi elementar tornar público o local que historicamente esteve sacralizado e protegido de qualquer intervenção externa: a família.

Para cumprir com esta demanda houve a articulação das feministas, da sociedade civil organizada e de iniciativas em torno dos tratados internacionais que lograram a promulgação da Lei 11.340/2006 (BRASIL, 2006, online) ou Lei Maria da Penha. Ditados populares, repetidos de forma jocosa deixaram de fazer sentido, como: "em briga de marido e mulher não se mete a colher" ou "ele não sabe porque bate, mas ela sabe porque apanha". Notoriamente o problema adquiriu dimensão pública e política, passando a ser responsabilidade de todos os cidadãos e todas as cidadãs, juntamente do Poder Estatal, coibir a violência doméstica e familiar contra a mulher.

Foi conquistada, pela primeira vez, uma lei com objetivo combater os variados tipos de violência contra a mulher, buscando uma intervenção ativa, incisiva e em outros casos educativa para por fim a discriminação de gênero ainda tão presente nos lares brasileiros. Criaram-se mecanismos para gerar garantias jurídicas e sociais no âmbito do direito, além de explicitar as consequências da enraizada cultura patriarcal presente em todos os espaços de sociabilidade humana.

Lograram os chamados Juizados Especializados em Violência Doméstica e Familiar contra a Mulher (JEVDFMs). Órgãos da justiça ordinária (comum), com competência civil e criminal. Passaram a ser os locais indicados para que tramite o processo e a execução das causas decorrentes da violência doméstica. Estes, em tese, dispõem do suporte necessário para atender as agredidas através de assistência oferecida pela equipe multidisciplinar integrada por profissionais especializados nas áreas psicossocial, jurídicas e de saúde, além de curadorias e serviço de assistência judiciária. 
Os JEVDFMs criam condições para que as medidas de punição, proteção, assistência e prevenção sejam aplicadas integralmente. E o compromisso com as convenções internacionais de proteção aos direitos da mulher (CEDAW e a Convenção Belém do Pará), a Política Nacional de Enfrentamento à Violência Contra a Mulher e o Pacto Nacional de Enfrentamento à Violência contra a mulher, envolvem princípios direcionadores dos funcionários públicos que atuam nos Juizados e também a própria polícia. Ou seja, as atribuições deste Juizado são distintas de todas as outras e visam dar condições objetivas para que as mulheres superem as situações de violência.

Outra inovação extremamente importante para gerar garantias sociais e jurídicas, foi a vedação da aplicabilidade dos Juizados Especiais Criminais (JECRIMs) nos casos de violência doméstica ou familiar contra a mulher. $\mathrm{O}$ art. 41 da Lei Maria da penha é taxativo ao dispor que “[...] aos crimes praticados com violência doméstica e familiar contra a mulher, independentemente da pena prevista, não se aplica a Lei ${ }^{\circ} 9.099$, de 26 de setembro de 1995."

A Lei 9.099/1995 criou institutos despenalizadores que tornassem os processos mais céleres e informais, por meio da economia processual, a oralidade, entre outros princípios aplicados às contravenções penais, aos crimes cuja pena não exceda dois anos e delitos de lesão corporal leve e lesão culposa. As medidas principais aplicadas nestes casos são: o acordo civil, a transação penal, suspensão condicional do processo e aplicação imediata de pena não privativa de liberdade.

Neste ínterim, a autoridade policial apenas redige um termo circunstanciado que é encaminhado ao juiz, sem necessidade de elaborar um inquérito policial. Posteriormente, na audiência preliminar é facultada a realização de acordos que levam a composição de danos e consequente extinção de punibilidade do agente. O Ministério Público, neste ínterim, poderá propor a transação penal ou a suspensão condicional do processo, o que gera a extinção do processo e afasta a reincidência do réu (art. 89, Lei 9.099/1995). E obedecendo ao ligeiro andamento do processo, adota-se nesta etapa o procedimento sumaríssimo.

Por muito tempo os delitos cometidos no ambiente doméstico, tendo os homens como agressores, foram considerados de pequeno potencial ofensivo e assim sendo, eram apreciados nos JECRIMs. A demanda dos delitos relacionados à violência de gênero era altíssima, sendo estas as que mais sobrecarregavam essa instância. Já as respostas às mulheres vítimas de violência, também eram desastrosas, o que desencorajava o relato das experiências vivenciadas em seus lares. 
Ocorria uma verdadeira institucionalização da violência, a começar pelo tratamento dos delitos nos lares contra as mulheres como um crime de baixa lesividade, depois ao decorrer do processo, em que a mulher deveria manifestar a sua vontade em dar andamento a este, muito tempo após a prática do fato e na presença do ofensor. Não havia nenhum tipo de

amparo nas áreas da saúde, psicossocial, da Assistência Judiciária ou da Defensoria Pública. Em consonância com os princípios despenalizadores da Lei 9.099/1995 os juízes, quase nunca preparados para lidar com esses complexos casos de agressão, exigiam meros pagamentos de cestas básicas a mulher ou pagamento de penas pecuniárias, entre outras medidas como as supracitadas. Por fim, na maioria dos casos o processo era extinto e o réu não era considerado um reincidente.

Em outras palavras, praticamente não havia ações afirmativas por parte do Estado que interferissem nos cotidianos e absurdos casos de violência dentro das famílias. Nas brigas de marido e mulher, não se metia a colher! Estavam imunes os homens que tratavam as companheiras como propriedade e usavam de sua força para demonstrar poder. O direito, mais uma vez, apresentou sua opção pelo referencial masculino e se calou diante da misoginia escancarada nos Juizados Especiais.

Foi da luta de milhares e milhares de Marias da Penha no Brasil que uma nova lei aparece, deixando claro que a violência doméstica ou intrafamiliar é um problema histórico decorrido do tratamento desigual recebido pelas mulheres. Nada mais justo que corrigir a desigualdade com medidas protetivas também desiguais. $\mathrm{O}$ alcance da igualdade substancial mencionada no artigo $5^{\circ}$ da Constituição Federal depende de um papel ativo e incisivo institucional que diferencie as medidas judiciais tomadas na generalidade para uma específica postura diante da violência decorrente do patriarcado, machismo, androcêntrismo e misoginia. Todas e todos são responsáveis pelo seu combate e o Estado tem o dever de ser um instrumento propulsor de mudanças por meio de políticas públicas direcionadas as mulheres.

Ainda que seja óbvia a constitucionalidade da Lei 11.340/2006, este posicionamento não é unanime, existindo diversos magistrados e operadores do direito que consideram a existência da norma um descumprimento da Carta Maior, isto quando não fazem uso de argumentos religiosos, infundados e preconceituosos, e que naturalizam o machismo. Casos assustadores podem ser citados a título de exemplo e são úteis para explicitar o caráter androcêntrico ainda presente no direito. Como é o caso do relato do Juiz de Direito, Edilson Rumbelsperger Rodrigues, há poucos anos afastado pelo Centro Nacional de Justiça: 
A lei Maria da Penha é um conjunto de regras diabólicas. Se essa lei vingar, a família estará em perigo. Ora, a desgraça humana começou no Éden: por causa da mulher. As armadilhas dessa lei absurda tornam o homem tolo, mole. O mundo é masculino e assim deve permanecer. No caso de impasse entre um casal, a posição do homem deve prevalecer até decisão da Justiça, já que o inverso não será do agrado da esposa. (AQUINO, 2011, online).

O uso de má-fé das clausulas pétreas da Constituição Federal de 1988 foi feito por temor à possibilidade que foi apresentada as mulheres de dizerem "não" a qualquer ato violento e de enfrentar diretamente a seus agressores. Um sem número de juristas se indignaram diante da efetivação dos direitos das mulheres, também perante o reconhecimento destas como seres humanos, e fizeram uso do argumento jurídico de que combater a violência das mulheres significava favorecer a este grupo social em detrimento dos homens. Ora, assim como pontua Lenio Luiz Streck, não se discute a constitucionalidade do Estatuto do Idoso, do Código de Defesa do Consumidor ou ainda, da Lei dos Crimes Hediondos (quanto a diferenciação obrigatória no regime inicial do cumprimento da pena), então por que apontar a Lei Maria da Penha como lei que fere a isonomia e a igualdade? (STRECK apud CAMPOS, 2011, p. 98)

Neste sentido, diz Maria Berenice Dias:

Somente quem tem enorme resistência de enxergar a realidade da vida pode alegar que afronta princípio da igualdade tratar desigualmente os desiguais. Cada vez mais se reconhece a indispensabilidade da criação de leis que atendam a segmentos alvos da vulnerabilidade social. A construção de microssistemas é a moderna forma de assegurar direitos a quem merece proteção diferenciada. (DIAS, 2012, p. 1).

A Lei 11.340/2006 ou Lei Maria da Penha não fere princípios constitucionais e, portanto, não sofre vício de inconstitucionalidade. Esta constatação foi ratificada não só por doutrinadores e feministas das diversas áreas de estudo, como também pelo próprio Supremo Tribunal Federal. O órgão Colegiado decidiu, por maioria de votos, no dia 9 de fevereiro de 2012 pela procedência da Ação Direta de Inconstitucionalidade (ADI 4424) ${ }^{1}$ ajuizada pela Procuradoria-Geral da República (PRG) relativa aos artigos 12, inciso I; artigo 16 e artigo 41 da Lei 11.340/2006.

O STF interpretou a lei conforme o seu artigo 228, parágrafo 8 o: "O Estado assegurará assistência à família na pessoa de cada um dos que a integram, criando mecanismos para coibir a violência no âmbito de suas relações.” E esta assistência consistia

${ }_{1}$ Origem: Distrito Federal, Entrada no STF: 4 jun. 2010, Ministro Relator: Marco Aurélio. DJ n. 104, 10 jun. 2010. 
na proteção à mulher quanto a qualquer tipo de exigência por parte do Poder Judiciário de caráter intimidatório ou coercitivo.

Deixou de ser obrigatória a representação da mulher em crimes de ação pública incondicionada. Esta não era mais notificada para representação e a lide poderia tramitar sem a necessidade dela corroborar a vontade em ver apreciado o fato. Ou seja, deixa de existir o constrangimento às mulheres em repetidamente afirmar seu desejo a dar continuidade ao processo, possuindo o Ministério Público a legitimidade de promover a ação.

Além da representação, havia a discussão em torno do art. 41 da Lei Maria da Penha e diversas afirmações de que o artigo feria o artigo 98, inciso I, da Constituição Federal. O dispositivo prevê a criação dos Juizados Especiais Criminais e delega à legislação infraconstitucional a identificação das infrações penais de pequeno potencial ofensivo. $\mathrm{O}$ fato da Lei Maria da Penha não ser enquadrado nesta normativa e não permitir o uso das benesses do instituto, não afeta sua higidez. Por motivos que visam a concretização dos objetivos da lei em proteger a integridade física, psicológica, sexual, patrimonial, os JECRIMs se mostram inadequados e incompatíveis com as necessidades das mulheres vítimas de violência doméstica.

Os ministros quanto a estas questões foram unânimes em suas decisões, destoando da opinião majoritária apenas o ministro Cezar Peluso que usou como justificativa o desencorajamento da mulher em relatar a agressão temerosa com a futura condenação do réu. Ademais, pontua o seguinte:

Isso significa o exercício do núcleo substancial da dignidade da pessoa humana, que é a responsabilidade do ser humano pelo seu destino. O cidadão é o sujeito de sua história, é dele a capacidade de se decidir por um caminho, e isso me parece que transpareceu nessa norma agora contestada." (SUPREMO TRIBUNAL FEDERAL, 2012, online).

$\mathrm{O}$ argumento apresentado possui fundamento mas, predomina o entendimento de que seria um encargo imposto a mulher, depois de vencer a barreira do silêncio, ainda obter sob sua responsabilidade a instalação da ação penal. A discordância do ministro supracitado aliado a uma crítica feminista poderia ser sustentado pelo pensamento de que a mulher deve ser o agente com poderes para decidir sobre o futuro de seu companheiro agressor. Seria esta mais uma forma de empoderá-la e reafirmar que as mulheres não terão seu poder de escolha atribuído a terceiros. Porém, é sempre importante ponderar e questionar se na realidade o efeito não seria contrário ao esperado, terminando os casos de violência doméstica em omissão e silêncio. 
Em suma, a decisão proferida em sede da Ação Direta de Inconstitucionalidade, com caráter vinculante e de eficácia contra todas, não deve ser em nenhuma hipótese descumprida, podendo ser anulado o ato administrativo ou cassada a decisão judicial que afronte o decidido. A Lei Maria da Penha ou Lei 11.340/2006, deve ser cumprida na íntegra e não cabem mais argumentos que tentam deslegitimá-la ou questionar os direitos das mulheres de pleitearem por uma vida livre de violência.

\section{REFORMAS SOCIAIS E A INTEGRALIDADE DA LEI MARIA DA PENHA}

O direito é mais uma expressão da estrutura patriarcal reproduzida pela sociedade e instrumento que institui a primazia do androcêntrismo. A legislação, genericamente tratada, contribui com a perpetuação de um modelo desigual e atentatório aos direitos de um grupo social. O conjunto, em cada tipo penal, sua linguagem, a quantificação das penas, representa um todo simbólico que interfere diretamente na vida dos indivíduos e constroem um imaginário que pode culminar na exclusão e violência. Porém, assim como o direito pode revelar uma faceta violatória de direitos humanos através de suas dinâmicas de opressão e hierarquização, também pode reproduzir-se desde lógicas de emancipação e igualdade.

O reconhecimento positivo da violência doméstica é um modo simbólico de asseverar sua existência e desconstruir com a lógica sexista. A concepção complexa e relacional dos direitos humanos demonstra que este instrumento está em constante transformação e pode ser utilizado para trazer garantias sociais e jurídicas. É ingênuo e superficial desconsiderar que o direito sustenta uma estrutura de desigualdades sexual, econômicas, étnicas/raciais, etc, porém eliminá-lo em razão do papel que cumpre atualmente é abrir mão de mais uma ferramenta importante no processo de mudanças.

Neste sentido, não é possível considerar que a dimensão jurídico-procedimental seja suficiente para impulsionar mudanças substancias e tampouco que deve ser o único na pauta dos movimentos feministas. A esfera formal é mais uma maneira de explicitar que os agressores são os responsáveis pela violência perpetrada contra as mulheres e não o contrário, como também de romper com as dicotomias do espaço público e privado. Se o direito é uma esfera da organização do poder, as feministas não devem rechaçá-lo.

Outro fato a ser considerado é a integralidade da Lei 11.340/2006 e o seu funcionamento em rede, não restrito a métodos punitivos e que alcança propostas de sensibilização sócio-cultural. A começar pela inédita definição da categoria "violência doméstica”, advinda das orientações da Convenção Belém do Pará. Esta foi responsável pelo 
rompimento com a tradição jurídica de incorporar genericamente o fenômeno social da desigualdade de gênero a tipos penais incriminadores tradicionais. Ou seja, foi discriminado pela lei que a violência contra a mulher no espaço doméstico se difere de qualquer outro ato violento no corpo social e deve ser tratado com especificidade.

Em decorrência disto, a simbologia do direito também está presente ao considerar que os crimes de violência de gênero não são de menor potencial ofensivo e, portanto, as medidas descriminalizadoras da Lei 9.099/95 não devem ser aplicadas. A Lei Maria da Penha elenca suas próprias medidas de proteção à mulher que vão além da prisão cautelar e estão contextualizadas às dinâmicas de agressões. Assim as possibilidades apresentadas ao magistrado de combater este ciclo são céleres e facilitam o acesso das mulheres ao aparato judicial. Os magistrados, a partir da promulgação da Lei Maria da Penha, tem a opção de encaminhar da ofendida e dos seus dependentes a programa oficial ou comunitário de proteção ou de atendimento, também de escolher por medidas extrapenais ( guarda de filhos, separação judicial, alimentos, etc).

Ademais, a Lei inovou ao trazer uma nova definição de família, mais ampla e pautada pelo paradigma da afetividade. A violência de gênero foi reconhecida também no âmbito das relações homoeróticas, incluindo a possibilidade de processamento da mulher que no espaço doméstico, é agredida por sua parceira. O que se observa é a constitucionalização do direito de família e a insurgência de novos valores pautados na dignidade da pessoa humana.

E o principal avanço foi a criação dos Juizados Especializados em Violência Doméstica e Familiar contra a Mulher, com competência civil e criminal, que surge com o intuito de por fim as inúmeras esferas burocráticas enfrentadas para as mulheres que buscavam o Poder Judiciário. Para os movimentos feministas era inconcebível a fragmentação do processo que tramitava na Vara Criminal apartado das demandas encaminhadas às Varas de Família (esfera civil). Isto trazia maior morosidade ao processo e não tratava adequadamente o complexo problema da desigualdade de gênero. Demandas eram encaminhadas para distintos juízes como se não estivessem interligadas e não fossem provenientes de um mesmo conflito.

Outras características destes Juizados Especiais é o trabalho realizado conjuntamente e em rede pela Defensoria Pública, Ministério Público, as Equipes Multidisciplinares na área a da saúde, jurídica, psicossocial. É elementar para a efetividade da Lei 11.340/2006 e consequentemente ao combate da violência de gênero, o apoio por psicólogos, assistentes sociais , a garantia de assistência judiciária e acompanhamentos por profissionais da saúde. 
Além disso, a capacitação sob a ótica de gênero daquelas (es) que estão nas instituições e recebem as agredidas. Essas são reformas que permitiram a inclusão das pautas feministas nas Políticas Públicas de Estado e o tratamento da violência contra a mulher como um problema público.

Com a promulgação da Lei passaram a quantificar os casos de violência doméstica, houve um aprofundamento as pesquisas sobre gênero e novas estatísticas foram divulgadas para que houvesse uma análise comprometida sobre a temática. Na letra da lei está posta a necessidade de sistematizar dados para avaliação periódica dos resultados das mediadas adotadas, bem como de promoção e realização de campanhas educativas de prevenção voltadas ao público e a sociedade em geral visando à proteção aos direitos humanos das mulheres.

Assim, o que se nota é um trabalho integrado que não apenas aumentou e agravou penas, mas também determinou o funcionamento em rede de diversas instituições sociais. Foram reformas advindas do processo histórico de lutas dos movimentos feministas, exigindo a presença das pautas dos coletivos na legislação brasileira e políticas públicas. Justamente por isso, não esse restringem a criminalização, mas sim para a atuação interdisciplinar dos profissionais e uma participação crítica por parte dos operadores do direito.

Partindo do ponto de vista das correntes minimalistas conclui-se que é fundamental a contração ao máximo do sistema punitivo, substituindo as sanções penais por formas de controle não estigmatizantes, usando, por exemplo, as sanções administrativas ou civis. Ademais, encaminhar processos alternativos de socialização e controle do desvio buscando principalmente a abertura de espaço para maior aceitação social daquele que delinque. Tais posturas, não devem ter caráter paliativo ou assistencialista, pelo contrário, necessitam apostar em medidas subjetivas e que visem uma conscientização acerca dos problemas de classe, gênero, raça/etnia dos espaços de sociabilidade (BARATTA, 2002, p. 202).

Segundo Alessandro Baratta (2002, p. 201):

"Por isso, uma política criminal alternativa coerente com a própria base teórica não pode ser uma política de "substitutivos penais", que permaneçam limitados a uma perspectiva vagamente reformista e humanitária, mas uma política de grandes reformas sociais e institucionais para o desenvolvimento da igualdade, da democracia, de formas de vida comunitária e civil alternativas e mais humanas, e do contrapoder proletário, em vista da transformação radical e da superação das relações sociais de produção capitalistas. 
O alargamento do sistema penal de medidas alternativas se dá pela ampliação das formas de suspensão condicional da pena e de liberdade condicional, pela introdução de execução da pena detentiva em regime de semiliberdade, em outras palavras, uma total reavaliação do trabalho carcerário (BARATTA, 2002, p.203). A Lei Maria da Penha, neste contexto, apresentou medidas específicas que apesar de significar um endurecimento penal em alguns aspectos, trouxeram inovações que se encaixam na linha de pensamento crítica e feminista do direito. Houve um tratamento especial, interdisciplinar e em rede, pela primeira vez abordando a violência doméstica. Foram apresentadas diversas formas de superação desta situação por meio de trabalhos com os agressores e agredidas, bem como através do uso das medidas protetivas as mulheres em situação de vulnerabilidade.

Numa sociedade visivelmente desigual abrir mão de defender as garantias legais e constitucionais que regulam o exercício da função penal do Estado tornou-se uma armadilha aos movimentos feministas. Contentar-se com as "concessões" oferecidas em uma sociedade burguesa e patriarcal pode levar ao cerceamento de direitos fundamentais por parte grupos sociais diversos. O caminho para superação do direito penal não implica na negação de formas alternativas de controle social do desvio, mas sim, num uso racional e crítico do direito, ainda que seja para simbolizar a presença de seres humanos e suas demandas.

Escreveu Gustav Radbruch que a melhor reforma do direito penal seria sua substituição, não por um direito penal melhor, mas por qualquer coisa melhor que o direito penal (apud BARATTA, 2002, p. 207). E isto só será possível quando transformarmos o modelo de sociedade atual fundado no patriarcalismo, na opressão de classe e raça/etnia, devendo ser a transição para esta nova configuração social acompanhada por uma política criminal alternativa e dos constantes combates ideológicos.

Finalmente diz Baratta (2002, p. 208) que:

Se se aplica um conceito positivo, e não só um conceito negativo de desvio, se poderá dizer que a sociedade igualitária é aquela sociedade que deixa o máximo espaço ao desvio positivo. Porque, neste sentido positivo, desvio que dizer diversidade. E a sociedade desigual é aquela que teme e reprime o diverso, porque a repressão do diverso, em todos os sistemas normativos particulares em que ocorre, do direito à religião, à escola, à família, é uma técnica essencial para a conservação da desigualdade e do poder alienado. Eis aqui porque quanto mais uma sociedade é desigual, maior é a inflação das definições negativas do desvio. 
E este é um dos maiores desafios da Lei Maria da Penha: por fim a cultura misógina e patriarcal. Além dos aspectos penais a norma carrega um conteúdo sensibilização acerca da desigualdade de gênero refletido nas políticas públicas previstas e o abertura que dá para a ampla participação dos movimentos sociais. O direito abriu portas para o uso alternativo e combativo da norma, demonstrando que ainda que seu caráter seja androcêntrico, faz parte de um processo de transformação as mulheres ocuparem espaços na esfera institucional. Nunca deve-se restringir as pautas feministas e a busca pela superação de nosso modelo político, econômico e cultural ao direito mas, também, jamais eliminá-lo como instrumento de luta. É direito fundamental das mulheres a utilização de todos os meios para efetivação de seus direitos humanos e a concretização das previsões de sua Carta Magna. Ainda que cause desconforto e polêmica geral, somente mulheres empoderadas e presentes em todos os espaços podem reverter situação histórica de opressão e violência.

\section{CONCLUSÕES}

Conclui-se que o reconhecimento dos direitos das mulheres consiste numa maior aplicabilidade de leis como a Maria da Penha, com conteúdo democratizante para as mulheres e que propõe o fim da violência machista e patriarcal dentro da família. Adotar uma perspectiva de gênero para fazer uma leitura da normativa constitucional e ordinária, torna-se elementar para os juristas e profissionais do direito que ainda são fortemente influenciados pela cultura androcêntrica.

O intuito está na criação de uma sensibilidade de gênero que possibilite a atuação dos profissionais do direito para além do formalismo jurídico, ademais de criar condições objetivas para que as mulheres possam prevenir e superar as dinâmicas de violência e atos atentatórios a sua dignidade. É fundamental consolidar uma rede integrada de atendimento às mulheres vítima de violência formada por profissionais qualificados e capacitados a partir dos aportes da teoria crítica e feminista.

A efetivação de direitos fundamentais se dá pelo maior grau de humanização e aproximação sócio-histórica das relações e experiências intersubjetivas. Por meio das ações dos seres humanos sobre o mundo concreto que estes e estas constróem os espaços de dignidade, podendo ser tanto produtos de práticas históricas de exclusões, dominações e lógicas de império, como também, resultado de uma articulação como agentes da transformação substancial da realidade. 
Por fim, propõe-se segundo a metodologia da costarriquense Alda Facio Montejo a utilização testemunhos de mulheres vítimas de violência para explicitar a natureza das relações reproduzidas na sociedade, nas pesquisas tanto acadêmicas quanto realizadas por iniciativas governamentais. Considera-se esta uma maneira de denunciar desde as experiências das próprias sujeitas, as formas assimétricas assumidas pela família e legitimadas pelas instituições (MONTEJO, 1999, p.5)

É essencial a criação de condições objetivas por meio de garantias jurídicas e sociais para que as mulheres superem as situações de violação de direitos humanos e ressurjam destas experiências ao criarem consciência de sua condição como sujeito feminino, também possuidor de direitos fundamentais. A criação de um Estado Democrático de Direito depende de uma sociedade que tenha espaços à todos e todas com liberdade, autonomia e livre de qualquer violência.

\section{REFERÊNCIAS}

ALVARENGA, Lúcia Barros Freitas. Discriminación y violência contra la mujer: una cuestión de género. Porto Alegre: Núria Fabris, 2011.

AQUINO, Ruth de. O mundo é masculino e assim deve permanecer. Época, São Paulo, 25 fev. 2011. Disponível em: http://revistaepoca.globo.com/Revista/Epoca/1,EMI21440915230,00.html. Acesso em: 23 de jun. 2013.

BARATTA, Alessandro. Criminologia crítica e crítica do direito penal: introdução à sociologia do direito penal. Tradução de Juarez Cirino dos Santos. 2. ed. Rio de Janeiro: Freitas Bastos, 1999.

BEAUVOIR, Simone. O segundo sexo: A experiência vivida. Rio de Janeiro: Nova Fronteira, 1980.

BRASIL. Supremo Tribunal Federal. Tribunal Pleno n 4424. Relator: Marco Aurélio. Brasília, DF, 09 de janeiro de 2012. Diário de Justiça Eletrônico.

CASTELLS, Carmen. Perspectivas feministas en teoría política. Barcelona, Paidos, Estado y Sociedad 1996.

COBO, Robo. Hacia una nueva política sexual: las mujeres ante la reacción patriarcal. Madrid: Fuencarral, 2011.

DIAS, Maria Berenice. A Lei Maria da Penha na justiça. São Paulo: Ed. Revista dos Tribunais, 2008.

em: . Lei Maria da Penha: uma lei constitucional e incondicional. Porto Alegre. Disponível 
http://www.mariaberenice.com.br/uploads/maria_da_penha_uma_lei_constitucional_e_incond icional.pdf. Acesso em: 10 maio 2014.

GARGALLO, Francesca. Las ideas feministas latinoamericanas. Bogotá: Desde Abajo, 2004.

MONTEJO, Alda Facio. Cuando el género suena cambios trae: (uma metodologia para el análises de género del fenomeno legal). 3. ed. San José: C.R. INALUD, 1999.

. ; FRIES, Lorena. Feminismo, género y patriarcado. In: FACIO, Alda; FRIES, Lorena (Comp.). Género y Derecho. Santiago: LOM : LaMorada, 1999.

OSBORNE, Raquel. ; PETIT, Cristina Molina. Evolución del concepto de género: selección de textos de Beauvoir, Millet, Rubin y Butler. Empiria: Revista de Metodología de Ciencias Sociales, Madrid, n.15, p. 147-182, ene./jun. 2008. Disponível em: http://espacio.uned.es/fez/eserv.php?pid=bibliuned:Empiria-2008-15-0006\&dsID=Documento.pdf. Acesso em: 17 ago. 2015.

Apuntes sobre violencia de género. Barcelona: Belaterra, 2009.

RUBIN, Gayle. O Tráfico de Mulheres: notas sobre a "economia política" do sexo. Tradução de Christine Rufino Dabat, Edileusa Oliveira da Rocha, Sonia Corrêa. Recife: Ed. SOS Corpo, 1993.

SAFFIOTI, Heleieth. O poder do macho. São Paulo: Moderna, 1987.

SANTOS, Cecília McDowell. Da delegacia da mulher à Lei Maria da Penha: lutas feministas e políticas públicas sobre violencia contra mulheres no Brasil. Coimbra: CES, 2008. (Oficina do CES, 301). Disponível em:

http://www.ces.uc.pt/publicacoes/oficina/ficheiros/301.pdf. Acesso em: 15 jun. 2015.

STOLLER, Robert. Sex and Gender. Science House, New York, 1968.

STRECK, Lenio Luiz. Lei Maria da Penha no contexto do Estado Constitucional: desigualando a desigualdade histórica. In: CAMPOS, Carmen Hein de Campos (Org.). Lei Maria da Penha: comentada em uma perspectiva jurídico-feminista. Rio de Janeiro: Lumen Juris, 2011. 